\title{
Cerebral Modifications in Glaucoma and Macular Degeneration: Analysis of Current Evidence in Literature and Their Implications on Therapeutic Perspectives
}

\section{Raffaele Nuzzi \\ Alessio Vitale}

Eye Clinic, Department of Surgical Sciences, University of Turin, Turin, 10126, Italy
Correspondence: Raffaele Nuzzi; Alessio Vitale

Eye Clinic, Department of Surgical Sciences, University of Turin, Via Cherasco 23, Turin, I0126, Italy Email raffaele.nuzzi@unito.it; alessio. vitale@unito.it

\begin{abstract}
Glaucoma and macular degeneration are leading causes of irreversible blindness, significantly compromising the quality of life and having a high economic and social impact. Promising therapeutic approaches aimed at regenerating or bypassing the damaged anatomical-functional components are currently under development: these approaches have generated great expectations, but to be effective require a visual network that, despite the pathology, maintains its integrity up to the higher brain areas. In the light of this, the existing findings concerning how the central nervous system modifies its connections following the pathological damage caused by glaucoma and macular degeneration acquire great interest. This review aims to examine the scientific literature concerning the morphological and functional changes affecting the central nervous system in these pathological conditions, summarizing the evidence in an analytical way, discussing their possible causes and highlighting the potential repercussions on the current therapeutic perspectives.
\end{abstract}

Keywords: cerebral, modifications, glaucoma, macular degeneration, connections, activity

\section{Introduction}

\section{Rational}

Among the various diseases of ophthalmological interest, those with the highest impact on the general population in terms of prevalence and morbidity are macular degeneration (in particular, senile macular degeneration) and glaucoma. Maculopathy and glaucoma are in fact the second and third cause of blindness in the world after cataract. ${ }^{1}$

Glaucoma, in particular, is the leading cause of irreversible blindness worldwide. A recent study ${ }^{2}$ reported that $3.5 \%$ of the population, or about 64 million people, currently suffer from glaucoma. Of these, 5.7 million have a visual defect, and 3.1 million are blind. It is predicted that the number of people worldwide suffering from glaucoma will rise to 111.8 million by 2040 .

"Macular Degeneration" is a term that includes several distinct pathological entities in two groups: JMD (Juvenile Macular Degeneration), characterized by earlier onset and AMD (Age-related Macular Degeneration), typical instead of older age and especially over 60. Specifically, AMD, the most frequent of the two, accounts for $8.7 \%$ of all blind people in the world and is the most common 
cause of legal blindness in developed countries. ${ }^{3}$ It is estimated that its prevalence will increase as a result of the lengthening of average life expectancy, with the number of affected people in the world increasing from 9.1 million today to 17.8 million in $2050 .{ }^{4}$ The impact that these pathologies have on public health is therefore evident, and from this remark derives the interest in a wider possible understanding of the phenomenon. There is much evidence to suggest that the alterations resulting from these two pathologies are not limited to the retina alone, but also affect the central nervous system in both structural and functional terms. ${ }^{5,6}$ It is our aim, with this review, to summarise and compare the data currently available in the literature concerning the modifications occurring at the CNS level, to identify their likely causes and to discuss the implications they may have in the context of existing or developing rehabilitation and therapeutic strategies.

\section{Glaucoma}

The term glaucoma refers to a heterogeneous group of pathological entities, sharing an optic neuropathy characterized by the progressive degeneration of retinal ganglion cells and their axons, which results in optic atrophy and progressive loss of visual field, starting from the most peripheral areas up to the central vision. ${ }^{7}$ In particular, primary open-angle glaucoma (POAG) is the most common variant; ${ }^{8}$ other types of glaucoma are primary angle closure glaucoma (PACG) and normal tension glaucoma (NTG).

Although high intraocular pressure and/or insufficient optic nerve perfusion pressure have been identified as the main agents involved in glaucomatous damage, the exact pathogenic mechanism is still unclear today. It is interesting to point out that certain studies have shown similarities between the alterations existing in glaucoma and some primitive neurodegenerative pathologies affecting CNS such as Alzheimer's Disease, ${ }^{9-11}$ in particular regarding $\beta$ amyloid accumulation, its neurotoxic role and the loss of ganglion cells, as is further discussed below. In this respect instrumental imaging, which is widely used in the clinical assessment of glaucoma, allows to evaluate some common features: in glaucoma Optical Coherence Tomography (OCT) typically detects a thickness reduction of peripapillary RNFL (Retinal Nerve Fiber Layer) and macular GCC (Ganglion Cell Complex) as a result of ganglion cells degeneration: this structural analysis allows,especially with the assessment of GCC thickness, an early objectification of glaucomatous damage even in early stages before the onset of visual field deficit. ${ }^{11-13}$ Likewise, in Alzheimer's Disease (AD, the most common neurodegenerative cause of dementia ${ }^{14}$ ) OCT analysis has revealed a reduced thickness of GCC and RNFL, for which neuronal retrograde degeneration is one of the main plausible hypotheses taken into account. ${ }^{15}$ Even more interesting are the results obtained through OCTangiography (OCT-A), which allows the evaluation of the retinal blood vessels: the retinal vascular network has many similarities with the cerebral vasculature, potentially reflecting the modifications occurring in some neurodegenerative diseases such as $\mathrm{AD},{ }^{9,16}$ In glaucoma, the existence of an unstable ocular perfusion has been previously demonstrated in the optic nerve, retina, and extraocular level, ${ }^{17}$ either due to IOP fluctuation or to a to primary vascular dysregulation, which is responsible for both ischemic damage and subsequent reperfusion injury to the ganglion cells: ${ }^{18}$ moreover, using OCT-A it was possible to observe an effective reduction of macular microvascular flow, particularly in the superficial retinal plexus. ${ }^{19-21}$ This flow disturbance would lead to a reduction in the thickness of GCC and RNFL, anatomically more susceptible to this impairment, showing an association between visual field defect, flow reduction and thinning of the layer. ${ }^{22}$ Interestingly, a reduction in macular flow has also been observed in $\mathrm{AD}$, but this time involving both the superficial and deep retinal plexus. ${ }^{16,23,24}$ It has been hypothesized this alteration could be produced by intraretinal deposition of $\beta$ amyloid, which has been identified in AD patients, causing both a mechanical compression on capillaries and a physical obstacle to the diffusion of oxygen and nutrients: ${ }^{16}$ this would result in a metabolic distress to ganglion cells and a subsequent degeneration and thinning of the GCC, which correlates with the disease severity. ${ }^{16}$ To date, the main therapeutic strategy for glaucoma is lowering IOP through the use of hypotonic drugs or surgery. This approach can be accompanied by nutritional supplementation for neuroprotective purposes. ${ }^{25}$ However, many therapeutic options are currently being studied and developed, such as glial cell modulation, stem cell therapy, gene therapy. ${ }^{26}$ These approaches aim at restoring the correct functioning of ganglion cells and allowing a renewed flow of visual information to the brain: it must be underlined, however, that such therapeutic proposals need, in order to be successful, the guarantee of an unaltered circuitry in the brain, which otherwise would not 
allow the correct signal processing once the restitutio ad integrum of neuroretinal structures has been obtained.

\section{Macular Degeneration}

Age-related Macular Degeneration (AMD) has ageing as its main risk factor, and causes macular damage primarily to the outer retinal layers, which results in the impossibility of processing the light stimulus into a nerve signal and therefore the loss of the central portion of the visual field. ${ }^{27}$ Juvenile Macular Degeneration (JMD) is a group of diseases, among which Stargardt's disease and Best vitelliform macular dystrophy are the main ones, with onset during childhood/adolescence. These diseases lead, similarly to AMD, to degeneration of the photoreceptors at the macular level, with loss of the central visual field. This time, however, the cause is to be found in metabolicstructural defects at the cellular level, on a genetic basis. Similar to AMD, the final stage of the pathology involves central neuroretinal atrophy.

Current therapies are directed in particular towards the neovascular form of AMD, through the use of intravitreally administered anti-VEGF molecules. No definitive therapies currently exist for the dry form of AMD and JMD. Therapeutic strategies are under development ${ }^{28-34}$ including pharmacological stimulation of neuroplasticity through Chondroitinase-ABC, macular surgery, prosthetic implantation, gene therapy; again, as with glaucoma, we are therefore faced with therapeutic perspectives that aim to obtain, at least in part, a restitutio ad integrum of the damaged retinal structure. In light of this, it is clear the importance that a modification of the network of neuronal circuits in charge of processing the visual signal following the pathological damage at retinal level may have, which could hinder, once the functional restoration of the retina has been achieved, a correct processing of the information and frustrate the therapeutic effort.

\section{Methods}

\section{Search Strategy}

We looked for studies dealing with changes in the visual and/or cerebral pathway during glaucoma or maculopathy (AMD and JMD) evaluated using imaging techniques. This research was conducted on MEDLINE Daily, MEDLINE (Ovid), MEDLINE In-Process and Other Non-Indexed Citations, CENTRAL, EMBASE, Latin American and Caribbean Literature on Health Sciences (LILACS),
CINAHL (EBSCO), Trip Database and The National Institute for Health and Care Excellence (NICE). No date or language restrictions have been used in the search. Articles published until December 2020 have been included.

\section{Study Design}

In order to produce this review, we included randomized controlled trials, clinical trials, non-randomized comparative studies, cohort studies and case series. Case report, case series with less than 6 patients and articles with incomplete outcome data were excluded.

\section{Participants and Interventions}

We have included studies in patients with Primary Open Angle Glaucoma (POAG), Primary Angle Closure Glaucoma (PACG), Normal Tension Glaucoma (NTG), Age-related Macular Degeneration (AMD) and Juvenile Macular Degeneration (JMD). Functional damage could be both unilateral and bilateral. Stage of pathology was not considered as exclusion criteria.

We included studies using the following imaging techniques for the study of brain characteristics:

- Diffusion tensor MRI (DT MRI/DTI)

- Voxel-based Morphometry (VBM)

- Surface-based Morphometry (SBM)

- Functional Magnetic Resonance Imaging (fMRI)

- Resting-state fMRI (rs-fMRI)

- Arterial spin labelling (ASL) MRI

- Magnetic resonance spectroscopy (MRS)

Patients' characteristics are reported in Table 1.

\section{Data Sources and Studies Selection}

Research about macular degeneration has resulted in a total of 142 articles. After the exclusion of duplicated results, not relevant or not covered by inclusion criteria, we obtained a final number of 19 articles. For glaucoma, the number of articles initially identified was 1911. As a result of the selection process, a final number of 64 articles was obtained.

In particular, among the studies selected for macular degeneration, 6 involve AMD, 6 JMD and 4 both, with a total of 364 patients (47.8\% AMD; 52.1\% JMD) and 325 controls. Among those selected for glaucoma, 54 studies concern POAG, 7 PACG and 9 NTG, for a total of 1502 patients (79.4\% POAG; 10.4\% PACG; $10.2 \%$ NTG) and 1178 controls. 
Table I Demographic and Clinical Characteristics

\begin{tabular}{|l|c|c|c|c|c|c|c|}
\hline \multicolumn{2}{|l}{ N. Patients } & \multicolumn{4}{c|}{ Mean Age (in Yrs.) } \\
\hline AMD & JMD & CONTROLS & AMD & JMD & CONTROLS \\
\hline 174 & \multicolumn{2}{|c|}{190} & 325 & $74.1^{\circ}$ & $39.3^{\circ}$ & $47.6^{\circ}$ \\
\hline POAG & NTG & PACG & CONTROLS & POAG & NTG & PACG & CONTROLS \\
\hline 1192 & 156 & 154 & 1178 & $54^{*}$ & $53.9^{*} *$ & $49.9^{* * *}$ & $50.3^{* * * *}$ \\
\hline
\end{tabular}

Notes: ${ }^{\circ}$ Value subject to approximation - out of a total of studies 26 did not provide the average age but only the range; I did not provide data about age. Two studies shared the same patients; ${ }^{\circ}$ Value subject to approximation - out of a total of 19 studies 2 did not provide the average age but only the range; I did not provide data about age; *Value subject to approximation - out of a total of 45 studies 2 gave the average age of a group consisting of POAG and NTG without distinction between the two subgroups; 2 gave the average age of a group consisting of POAG and PACG without distinction between the two subgroups; I did not give the average age but only the range; **Value subject to approximation - out of a total of 8 studies, 2 gave the average age of a group consisting of POAG and NTG without distinction between the two subgroups; I did not give the average age but only the range; ****Value subject to approximation - out of a total of 7 studies 2 gave the average age of a group consisting of POAG and PACG without distinction between the two subgroups; ****Value subject to approximation - out of a total of 52 studies I did not provide the average age but only the range; 3 did not provide a given age.

\section{Results}

\section{Analysis of Morphological and Functional Alterations Detected in the CNS During Glaucoma (POAG, PACG, NTG)}

The structure of the white matter has been studied using indirect (DTI) and direct (VBM) methods. These studies have shown the presence of structural microalterations along the entire visual pathway, involving the optic nerve, ${ }^{35-40}$ optic tract, ${ }^{41-46}$ optic radiation ${ }^{35,36,41-59}$ up to visual areas BA17, BA18 and BA19 at occipital lobe level $^{60-62}$ [Figure 1]. These findings are based on the analysis of fractional anisotropy (FA), i.e. a quantification of the directionality of water diffusion within a voxel, which was found to be lower than normal; a change in the value of FA, in particular a reduction in it, is an indirect sign of microstructural damage in the white matter. Other variables considered were the increase in
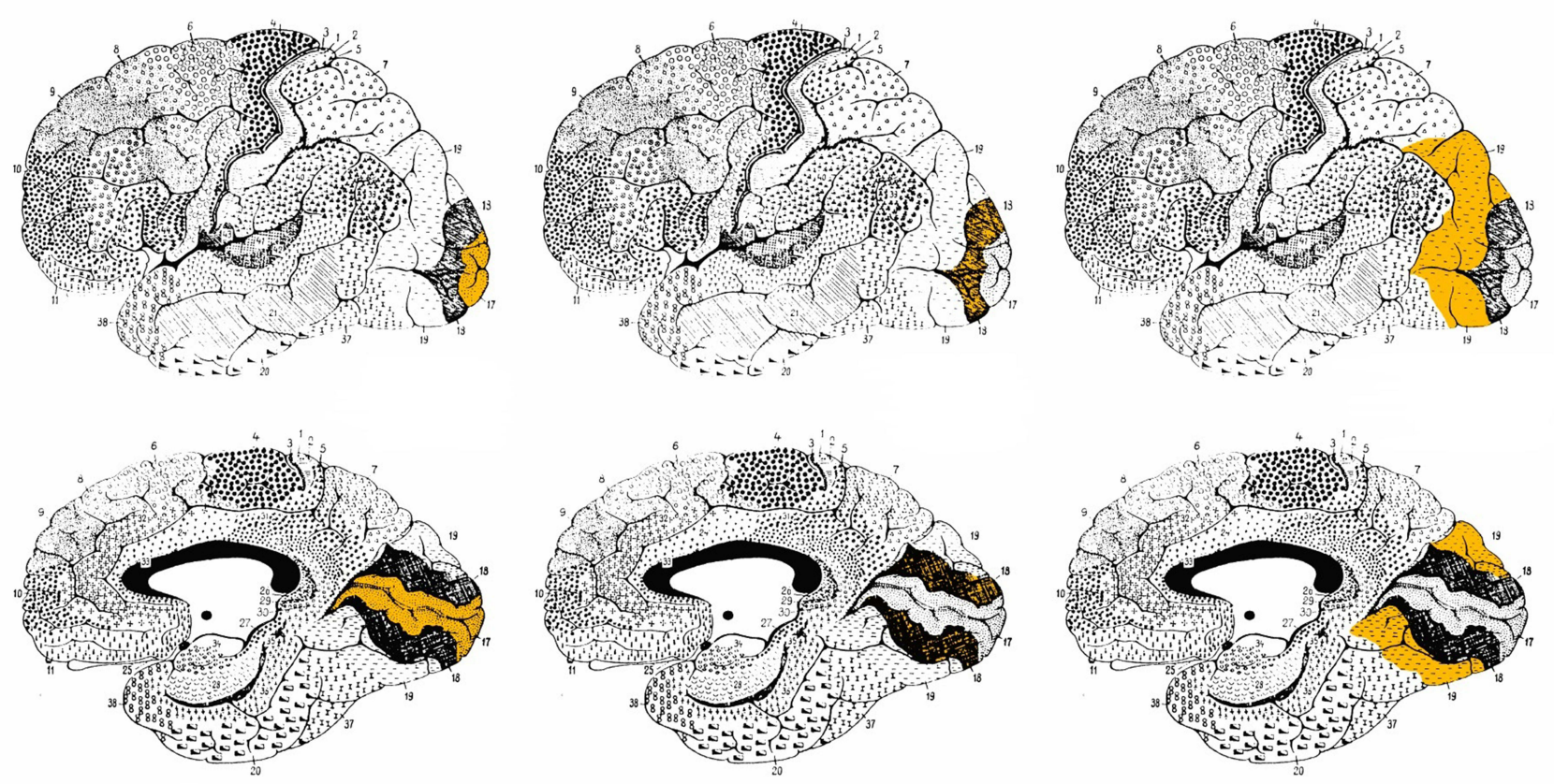

A

B

C

Figure I (A) Brodmann area 17, lateral and medial view. (B) Brodmann area 18, lateral and medial view. (C) Brodmann area 19, lateral and medial view.

Notes: Adapted from: Brodmann K. Vergleichende Lokalisationslehre der Grosshirnrinde in ihren Prinzipien dargestellt auf Grund des Zellenbaues [Comparative localization theory of the cerebral cortex presented in its principles on the basis of the cell structure]. Leipzig: Johann Ambrosius Barth Verlag; I909. German. ${ }^{29}$ 
mean diffusivity (MD) and radial diffusivity (RD), also a sign of axonal damage. We cannot consider these observations as a reduction of white matter in the strict sense, but certainly as alteration and damage of the structures belonging to it. Even more interesting was the detection of alterations involving numerous brain areas outside the proper visual pathway. Abnormal values of FA and MD in DTI-MRI technique, therefore index of axonal damage, were detected in corpus callosum, hippocampus, parietal lobes, supramarginal gyrus, upper longitudinal fasciculus, rostrolateral prefrontal cortex and lower frontal gyrus $^{43,46,62,63}$ in all types of glaucoma (POAG; PACG; NTG); these brain structures are linked to superior visual and cognitive functions. Furthermore, an altered signal was detected in the fronto-occipital fasciculus (visualspatial function), longitudinal fasciculus, inferior-frontal fasciculus (visual memory), putamen, caudate nucleus and internal capsule (interaction between vision and movement, orientation). ${ }^{64}$ These alterations have shown direct correlation with disease progression: in particular, FA parameter is negatively correlated with the severity of glaucomatous disease in terms of RNFL, visual field and cup-to-disc ratio alterations; MD and RD are instead positively correlated. ${ }^{35,37-41,45,52,54,58}$ The cause of these modifications seems to be a form of transsynaptic neurodegeneration extending in an anterograde and retrograde sense along the structures involved in visual function, starting from the ganglion cells to the upper brain areas with associative function. ${ }^{49,65}$ Of great interest is the result reported by Boucard, ${ }^{63}$ who reported microstructural alterations (in terms of reduced FA in DTI) in the corpus callosum in a group of patients with normotensive glaucoma. This observation, in a brain structure so extraneous to visual function, may suggest a pathogenic component that can no longer be explained by anterograde and/or retrograde neuronal degeneration alone, but rather as an additional and independent mechanism of neurodegeneration acting in glaucoma, with features partly reminiscent of Alzheimer's disease. ${ }^{66}$ Microstructural alterations appear associated with a loss of density and volume of white matter. Direct measurement of white matter was performed using the Voxel-Based Morphometry (VBM) technique, identifying a volumetric reduction along the entire pathway (optic nerves, chiasma, optic traits, CGL, optic radiation). ${ }^{50}$ Again, these alterations, particularly in optic radiation, were directly correlated with both severity of optic nerve damage (optic atrophy) and loss of visual field.

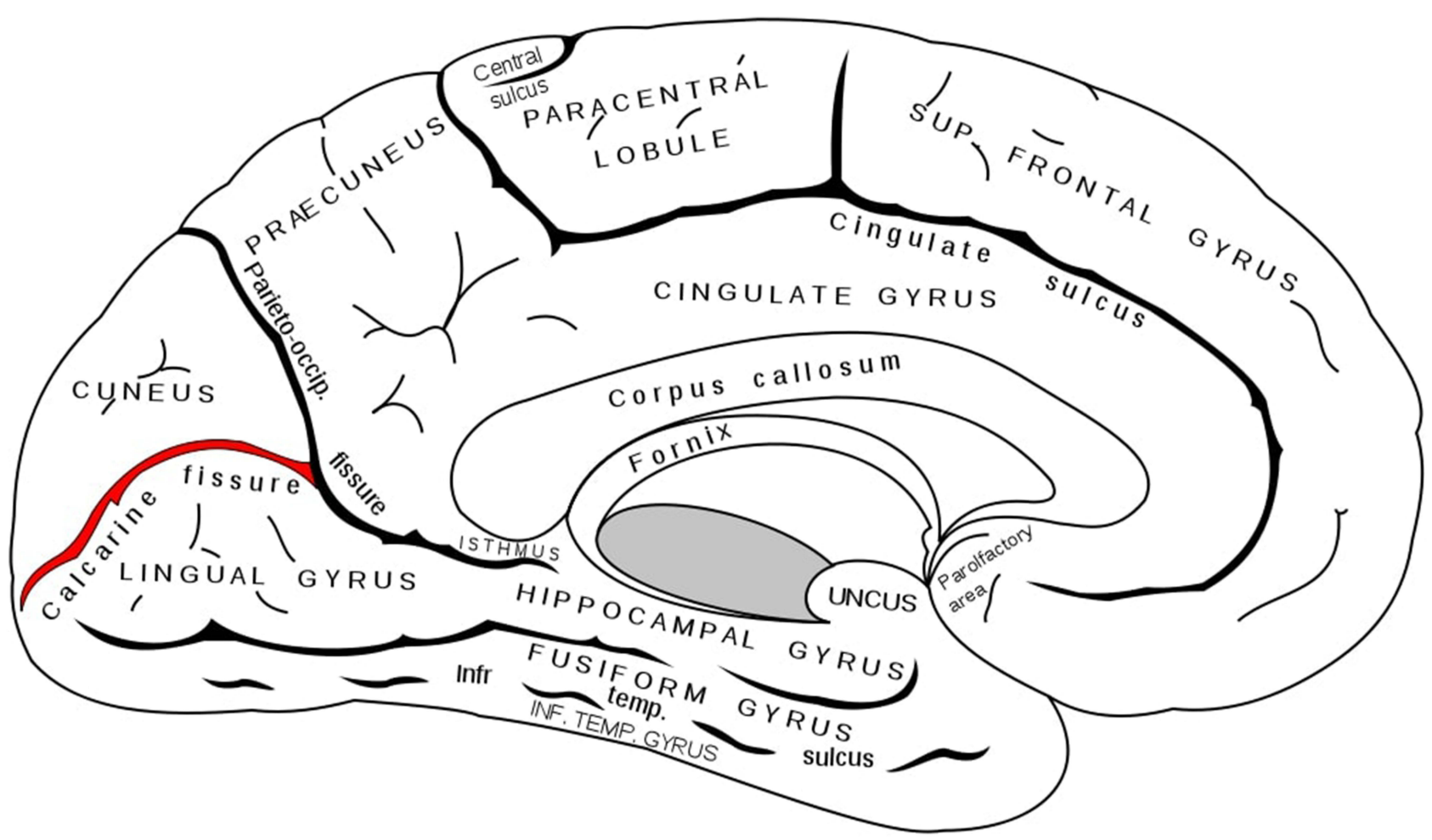

Figure 2 Calcarine fissure (in red), medial view. Gray H. Anatomy of the Human Body. Philadelphia: Lea \& Febiger; $1918 .^{130}$ 
Grey matter has also been subject of attention. Many studies, through the use of VBM, have reported a significant reduction in volume and density of grey matter within the primary visual cortex..$^{42,43,46,50,59,64,67-71}$ It should be noted that this reduction was significant only in the most anterior part of the calcarine fissure, reinforcing the idea of retinotopically distributed damage ${ }^{72}$ [Figure 2]. This data acquires even more significance if compared with MD (see below), where the reduction in volume is concentrated in the posterior part, where the projections coming from the central area of the retina are located. A volumetric reduction was also detected outside the visual cortex, at lingual gyrus, postcentral gyrus, superior frontal gyrus, inferior frontal gyrus, rolandic operculum, cerebellar cortex, hippocampus
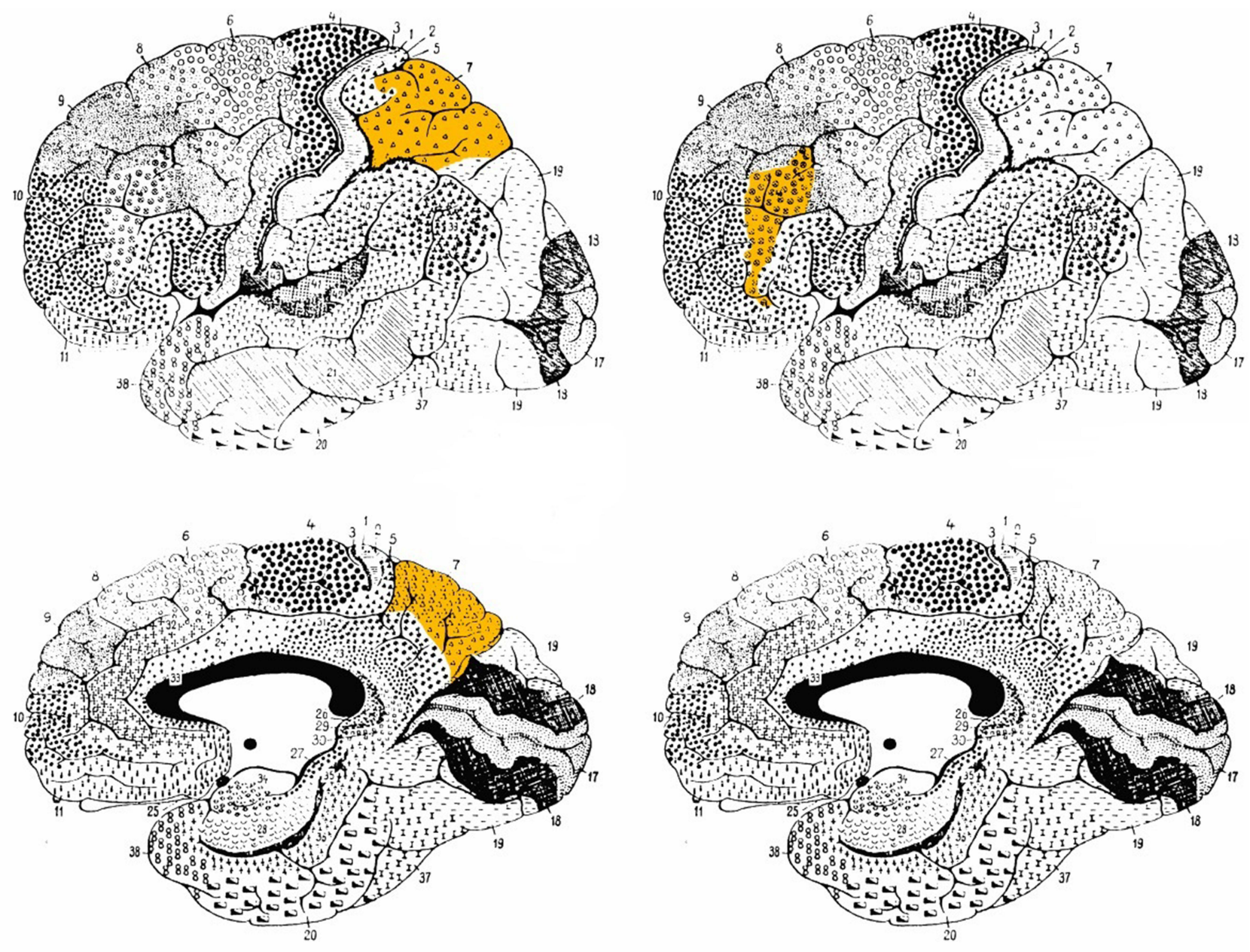

A and mean temporal circumvolution. ${ }^{42,67,68,73}$ Again, the involvement of such structures can be explained considering the existing connections between them and the visual area for the performance of higher functions related to vision (writing, movement and coordination, memory, face recognition). These alterations, as well as for white matter, are explained by a mechanism of transsynaptic diffusion of cell death signals triggered by the degeneration of ganglion cells both in an anterograde sense ${ }^{74}$ and, especially for areas not directly involved in the visual pathway, in a retrograde. ${ }^{63,75}$ Again, the positive correlation between the extent of brain alteration and the severity of glaucomatous damage has been demonstrated. ${ }^{67,70,71,73}$ Particularly suggestive were the alterations found in areas such as

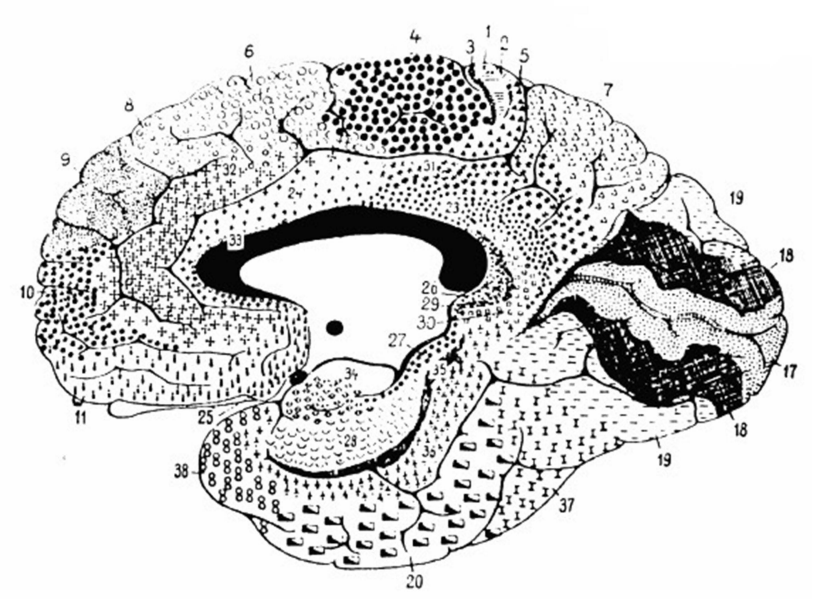

B

Figure 3 (A) Brodmann area 7, lateral and medial view. (B) Brodmann area 46, lateral and medial view. Brodmann K. Vergleichende Lokalisationslehre der Grosshirnrinde in ihren Prinzipien dargestellt auf Grund des Zellenbaues [Comparative localization theory of the cerebral cortex presented in its principles on the basis of the cell structure]. Leipzig: Johann Ambrosius Barth Verlag; 1909. German. ${ }^{129}$ 
amygdala, hippocampus, orbitofrontal cortex and superior parietal lobule which, although not directly related to the elaboration of visual informations, are involved in other neurodegenerative disorders such as Alzheimer's disease, suggesting again similarities between the two pathological conditions. ${ }^{42,71}$

Even so, not all the studied areas showed volumetric reduction; on the contrary in some of them the volume was increased: this is the case of midbrain, left brainstem, frontal gyrus, cerebellar vermis, left inferior parietal lobule, caudate nucleus, thalamus, precuneus, and Brodmann areas 7, 18, and 46 [Figures $3 \mathrm{~A}$ and $\mathrm{B}$ and $1 B]$. As an explanation for this finding, it has been suggested that it may be a consequence of neuronal damage (which, by causing cell swelling and microglia activation, may lead to an increase in volume) or a form of neuroplasticity linked to a greater functional activation and consequent increase in dendritic arborisation. This alteration in volume, however, has not always been associated with a functional modification: this latter data makes us more inclined towards the first etiological hypothesis. ${ }^{59}$ Alongside these various morphological alterations there were also modifications in brain activity: through the use of fMRI a reduction in the activation of the primary visual cortex following visual stimulation has been identified in POAG, ${ }^{48,55,59,76-81} \mathrm{NTG}^{48,78,81}$ and PACG. ${ }^{82}$ Using rsfMRI, and measuring cerebral blood flow by arterial spin labeling MRI, ${ }^{83,84}$ a reduction in neuronal activity was also observed in resting state in visual cortex, motor cortex, somatosensory cortex and Default Mode Network (DMN, a major neuronal network comprising prefrontal cortex, medial temporal lobe, inferior parietal lobe, posterior cingulate cortex, angular gyrus and hippocampus, that deactivates during goal-directed tasks). Neuronal connectivity in resting-state ${ }^{61,84-86}$ was also found to be decreased bilaterally, both in areas directly related to the visual process (primary visual cortex and superior visual areas) and indirectly, such as between visual cortex and $\mathrm{R}$ superior/inferior temporal gyrus, R/L fusiform gyrus, L inferior frontal gyrus, L middle occipital gyrus, $\mathrm{R}$ angular gyrus, $\mathrm{R}$ superior occipital gyrus, $\mathrm{L}$ postcentral gyrus, R precentral gyrus, anterior lobe of the left cerebellum. On the contrary, increased connectivity was present towards L cerebellum, $\mathrm{R}$ middle cerebellar peduncle, $\mathrm{R}$ middle frontal gyrus and extra-nuclear gyrus. This reduction in functional connectivity appears to correlate with visual field deficit and glaucoma stage, ${ }^{84}$ although a demonstrated cause-effect relationship is lacking to date ${ }^{85}$ the reduced connectivity involving visual areas has also been related with thickness reduction of retinal RNFL. ${ }^{61}$ The reason for all these modifications is not clear; it has been suggested that the reduced functional activity and connectivity may be secondary to transsynaptic degeneration and/or decreased visual information flow. $^{43,87}$ The increase in connectivity, often coexisting with an increased volume involving associative areas $^{59,67-69}$ is probably secondary to the reduction in GABAergic inhibitory signalling which, through visual feedback, visual areas normally exert on some higher areas. ${ }^{88}$ In summary, in glaucomatous patients neuronal connectivity was found to be reduced in the context of the areas inside the visual cortex and between the visual cortex and the designated areas for visual memory, working memory, attention and motor coordination; it was instead found to be increased between the visual cortex and the areas designated for cognitive association and limbic system: $:^{65,75}$ it is suggestive to associate these morpho-functional modifications with some cognitivebehavioural alterations described in patients affected by glaucoma: the first observation can be associated with impairment of memory, coordination and posture, the second with the greater prevalence of anxiety and depression demonstrated in subjects suffering from glaucoma. ${ }^{89,90}$ The modified functional connectivity involving the amygdala has also been related to the emotional impairment that is sometimes described in glaucomatous subjects. ${ }^{86}$ Also noteworthy is the altered functional connectivity between the visual network and the default mode network, involved in attention and executive function, whose nodal point (the posterior cingulate cortex) has demonstrated a close correlation with disease progression in Alzheimer's. ${ }^{85}$ The same network also demonstrated a reduced neuronal activity at rest, again resembling $\mathrm{AD}^{87}$ More recent studies have also identified $^{60}$ a reduction in connectivity from the BA17 primary visual area to the BA18 and BA19 superior visual areas, and vice versa a greater connectivity from the superior ones to the primary; increased connectivity was also found between the primary visual area and extrastriated associative areas such as fusiform gyrus (shape, face, colour recognition), precuneus gyrus, posterior cingulate cortex (visual memory, visuospatial attention) and somatosensory cortex: there is so a situation of reorganization within the visual cortex and between the visual cortex and the associative areas, with a flow of information that is overall reduced in a hierarchically ascending sense (from 
the primary visual area to the superior visual areas to the associative areas) and vice versa increased in a descending sense. The meaning of these observations remains uncertain, it is probable that could be a reorganization aimed at compensating the glaucomatous damage that involves a deficit of information coming from the retina to the visual cortex; the same thing has been hypothesized to explain the increased resting activity of prefrontal cortex, L superior temporal gyrus, L inferior parietal lobule, $\mathrm{R}$ middle cingulate cortex. ${ }^{87}$ These modifications are once again associated with some features found in glaucomatous patients, such as trouble in visuomotor coordination and somatosensory impairment. Similarly, a reduced connectivity between visual cortex, supramarginal gyrus (involved in oculomotor control), superior sensorimotor areas and cerebellum seems to be reflected in a difficult postural control and an increased risk of falling. ${ }^{91,92}$

\section{Analysis of Morphological and Functional Alterations Detected in the CNS During Macular Degeneration (AMD, JMD)}

Structural alterations were detected in both grey and white matter. The white matter was volumetrically reduced along the entire visual pathway, although with some differences between JMD and AMD: in the first case all structures were involved (optic nerve, chiasm, lateral geniculate bodies, optic radiations and visual cortex), while in the second case only those downstream of the lateral geniculate bodies (lateral geniculate bodies, optic radiations and visual cortex). The volumetric reduction observed in patients with JMD also appeared to be quantitatively greater: this data in particular would seem to be linked to the greater primitive alteration existing in JMD compared to AMD, consequent to an anatomo-functional retinal damage on average wider, and therefore with greater visual field involvement. ${ }^{93}$ Another difference was the involvement, once again in terms of volumetric reduction, of the frontal lobe white matter in AMD patients only; this observation was explained as a result of a coexisting non-specific senile degeneration in patients who, compared to the JMD group, are on average older. With regard to grey matter, its reduction has been recorded at the level of the occipital pole ${ }^{93-96}$ in correspondence with the calcarine fissure, particularly in its posterior part. $^{94}$ This last detail is consistent with what discussed for glaucoma, where the anterior part is mainly involved, and supports the hypothesis of a damage distributed to the visual cortex with a retinotopic pattern, which in turn corresponds to the visual field deficit. These volumetric alterations are negatively correlated with the severity of visual field deficit and with the patient's reading speed. ${ }^{95}$ On the contrary, Olivo ${ }^{96}$ demonstrated in patients with JMD (and in particular Stargardt's disease) an increase in grey matter in the left supramarginal gyrus.

The reduction in the volume of grey and white matter has been explained as a consequence of a trans-synaptic degeneration related to central retinal damage, and distributed in a retinotopic way at a cerebral level. ${ }^{6}$ The increase in grey matter observed by Olivo is likely to have a compensatory meaning, since this area is involved in eye movement, and particularly in the adaptation of handeye coordination.

As far as functional alterations are concerned, all studies in the literature have found a reduced activation of the visual cortex in subjects suffering from macular degeneration, both AMD and JMD. ${ }^{97-99}$ This result was accompanied by some secondary findings: some areas outside the visual field (frontal and supplementary eye fields, prefrontal cortex, intraparietal sulci, parietal lobule) showed increased activity following visual stimulation compared to healthy subjects. This observation was related to the use, common in subjects with central visual field deficit, of a PRL (Preferred Retinal Locus), i.e. a retinal locus other than fovea, outside the degenerated area, used as a new point of focus of the image through an eccentric fixation. This method, which allows a discreet visual function to be achieved despite the macular pathology, requires however more advanced image processing and oculomotor coordination, and this effort justifies the activation of associative areas involved in ocular coordination such as those indicated above. In addition, subjects with stable PRL showed greater activation of the visual area (although less than healthy subjects) than subjects unable to use eccentric fixation. ${ }^{100-104}$ Not only that, but the use of a PRL led to an activation of the cortical area normally reserved to the projection of the fovea in $\mathrm{V} 1 ;^{101,105,106}$ this eventuality, sometimes recorded with discordant results in the studies available in literature, was observed especially during stimulus-related tasks, while it tended to be absent in case of passive viewing. To explain this, it has been hypothesized a remodelling of neural pathways thanks to a mechanism of neuronal plasticity, or an activation of task-dependent cortical connections normally inactivated by signals coming from the retina. In addition, it has been demonstrated $^{107}$ that the visual exercise, which allows the 
achievement of greater visual performance through the stabilization of the eccentric fixation, involves an increase in cortical response to retinal stimulation, particularly in the area of projection of the PRL. A countertendency result regarding functional connectivity was reported by Haak $^{108}$ which, in patients with Stargardt's disease, showed that the existing corticocortical connections between $\mathrm{V} 1$ and V2/V3 still retained their retinotopic characteristics almost intact, without substantial changes.

\section{Discussion}

The high social and economic impact of diseases with serious visual field deficits such as glaucoma and macular degeneration, and the inability to restore the retina once the damage has been established, have led to the use of rehabilitation therapy alongside medical therapy, for example through the use of computer-based vision training to maximise the sensitivity of residual vision areas, ${ }^{109}$ or a preferred paracentral retinal locus to be used as a new fixation point. ${ }^{110,111}$ These methods certainly benefit from a morpho-functional reorganization of brain circuits at the head of the visual processing, which can thus compensate for the damage consequent to the pathology; to date, the occurrence of such an eventuality, based on neuronal plasticity mechanisms and on the activation of normally silent secondary connections, seems to be plausible even if the evidence is not yet definitive. ${ }^{5,6}$ However, it should be pointed out that other therapeutic perspectives, which may be available in the near future, such as retinal ganglion cell transplantation, ${ }^{112}$ retinal prostheses, ${ }^{113,114}$ stem cell therapy ${ }^{115}$ and genetic therapy ${ }^{116}$ need instead the guarantee of an unaltered connectivity between retina and the brain which, if not maintained, could even result in a failure not allowing, once the retinal integrity is restored, the correct processing of the visual signal. It is therefore needed to summarise the current evidence regarding the morphological and functional alterations affecting the CNS in patients suffering from glaucoma and macular degeneration, and to compare the distribution of these alterations in the two pathologies deriving so the implications they could have on current rehabilitation techniques and future therapeutic possibilities.

The cerebral occipital pole is transversally involved in both glaucoma and maculopathy: a reduction in volume and density in the primary and superior visual areas has been recorded in both white and grey matter. The V1 area is involved in a retinotopic way (anterior in glaucoma, posterior in $\mathrm{MD}$ ). The retinotopic visual pathway is also involved: in all its structures in glaucoma and JMD; downstream of the lateral geniculated bodies in AMD. This volumetric reduction is accompanied by structural microalterations, affecting in particular the white matter, which can be explained primarily as a result of anterograde and retrograde transsynaptic degeneration, to be referred to the retinal damage and the consequent functional deprivation. However, a clear difference can be observed in the comparison between MD and glaucoma: the structural alteration in the first case is almost exclusively limited to the visual pathway and the visual brain areas (although with the exception of some observations ${ }^{93,96}$ involving areas external to the occipital lobe, but with a probable senile meaning or consequent to the rehabilitation training); in glaucoma, on the other hand, in addition to the occipital lobe many other areas, even distant from each other, are involved along the entire brain, affecting both white and grey matter with a severity directly proportional to the extent of glaucoma damage. For many of these structures it is possible to explain their involvement as they are implicated in the integration of visual function with higher functions, such as movement, memory, orientation, emotions, writing; other ones, however, are so unrelated to visual function that the co-presence of a parallel and separate neurodegenerative mechanism alongside the transsynaptic glaucoma-related degeneration is suspected, probably similar to the one that occur in other neurodegenerative diseases such as Alzheimer's. ${ }^{63}$ Morphological alterations are accompanied by functional alterations, also involving the brain to varying degrees between MD and glaucoma. Again, in macular degeneration has been recorded a decreased response involving only the visual cortex (with the exception of a few external areas, related to rehabilitation training and in particular to the effort due to the use of a PRL as an eccentric fixation locus). Functional alteration in glaucoma, on the other hand, has been shown to be widespread and extended to the entire brain, and in particular to areas related to memory, attention, orientation, coordination, object and face recognition. In these areas, brain activity was both reduced and increased, probably due to a transsynaptic degeneration consequent to the pathological damage, and on the other hand due to the reduced inhibition that visual areas normally exert on these associative areas through feedback.

What explanations can be given for this discrepancy in observations? First of all, it needs to be considered the different natural history of the two pathologies, which involve different areas of the retina. While glaucoma produces extensive retinal 
damage, primarily directed towards ganglion cells, involving first peripheral visual field and then, only in the advanced stages, the central field, macular degeneration causes photoreceptor damage limited to the central part of the retina, i.e. the macula, which corresponds to the ten-fifteen central degrees of the visual field. This neuroretinal degeneration is reflected in a different involvement of the nerve fibres starting from the retina towards the CNS (constituting the visual pathway formed by optic nerve, chiasma, optic tract, CGL and optic radiation), thus leading to a morpho-functional alteration quantitatively and qualitatively different at cerebral level, with a retinotopic distribution of the damage in the visual cortex.

Why so many areas outside the visual one are involved in glaucoma is still unclear. In the vast majority of cases these areas are actually related to visual function, but do not appear to be altered in course of macular degeneration: we can hypothesize that these superior functions (visuo-motor, visuo-mnemonic, recognition, orientation) use information coming mostly from the peripheral visual field, and they are therefore involved only during diseases affecting particularly the external part of the visual field; however, this hypothesis is not currently supported by evidence in literature. The distribution of functional alterations would seem to reflect that of morphological alterations. While the visual cortex is involved in both pathologies, and always with a decreased activity, in glaucoma there is involvement of several external areas, widespread throughout the brain, with a reduced or increased functional response. This last observation in particular has been related to the probable decrease of inhibitory feedback normally coming from the visual areas and directed to higher associative areas in response to the retinal stimulus. A link has been suggested between this altered brain activity and some impairment typically observed in glaucomatous patients, particularly in object identification, visuospatial function, visuomotor coordination and somatosensory functions. Such widespread brain involvement, even in areas not related to visual function, has also led to the hypothesis that there could be an additional neurodegenerative mechanism, not directly related to transsynaptic degeneration but, rather, more similar to what occurs in neurodegenerative diseases such as Alzheimer's. It should be noted that the existence of a possible correlation between Alzheimer's Disease and glaucoma has already been investigated previously, without however reaching definitive results. The hypothesis of a possible link between the two diseases arose from the observation of some shared characteristics: both diseases are age-related; ${ }^{117,118}$ they present progressive neurodegeneration; ${ }^{118,119}$ the deposits of tau protein and $\beta$ amyloid (major pathological features of $\mathrm{AD}$, accumulating in the brain) have been detected in the retina of both $\mathrm{AD}$ subjects and glaucoma subjects; ${ }^{118,119}$ APOE polymorphisms, strongly associated with $\mathrm{AD}$, have also been suspected to be involved in optic nerve damage and visual field defect in glaucoma, although the latter is a point still under discussion. ${ }^{118}$ The most recent systematic reviews and meta-analyses ${ }^{117,120)}$ conducted on the studies in literature, however, did not allow to reach a conclusive result, as many questions emerged: although a first analysis found a statistically significant increase of the risk of developing $\mathrm{AD}$ in glaucomatous patients, the results of the analysed studies appeared to be often contradictory and the studies were sometimes inadequately designed and poorly conducted. ${ }^{120}$ The high heterogeneity of study design and study population was suspected to be a source of bias so that, after stratifying by study type, the association between $\mathrm{AD}$ and glaucoma persisted only in the subgroup of case-control studies (more susceptible to selection bias and recall bias) while it disappeared in cohort studies. ${ }^{117}$ Even the great genetic heterogeneity of the two diseases under investigation (65 genes suspected to be involved in glaucoma, 31 in $\mathrm{AD}^{117}$ ) has been accused of being a source of bias if not adequately controlled; the same applies to other potential confounders (comorbidities, alcohol drinking, smoking), which were not always adequately controlled in the considered studies, and to the different diagnostic criteria used to define the diseases. The results of these systematic reviews, therefore, have been described as "hypothesis generating" and should be interpreted with caution. ${ }^{117}$ The association between Pseudoexfoliation Syndrome (PEX) and glaucoma has also been investigated because of some common features between the two diseases: the fibrillar extracellular material typical of PEX has been detected not only in the eye, but also in blood vessels, skin, kidneys, lungs, heart, and meninges; ${ }^{121}$ moreover, polymorphisms of the LOXL1 gene, ${ }^{122}$ as well as of the APOE gene, ${ }^{123}$ were initially associated with both PEX and $\mathrm{AD}$, although this association was later disproved. ${ }^{124,125}$ In addition, $\beta$-amyloid peptide has been demonstrated in aqueous humour of PEX patients. ${ }^{122}$ Despite these clues, after a first possible evidence of association between PEX and $\mathrm{AD},{ }^{126,127}$ subsequent populationbased studies (the major limitation of the previous studies was the hospital-based design with consequent possible selection bias) have rejected this correlation and excluded 
the hypothesis that PEX may be a risk factor for Alzheimer's Disease. ${ }^{122,128}$

Whether at least some of these morpho-functional alterations could be a sign not only of degeneration but also of occurred remodelling based on neuroplasticity is still under discussion. In the context of these pathologies, the evidence of remodelling has already been suggested, ${ }^{5,6}$ but to date there is no definitive evidence that these changes may reflect a real plasticity of the adult CNS following the pathological insult, rather than a simpler adaptation through the activation of normally silent collateral and secondary circuits. Obtaining definitive evidence in this area would have great repercussions in a therapeutic perspective: as discussed above, if a remodelling would certainly be useful within a rehabilitation path aimed at maximising the residual visual capacity and compensating for the lost one, a modification of the nervous circuits between retina and the brain, and between the different brain areas, could on the contrary compromise the potential results of therapeutic approaches still in development (cell therapy, gene therapy, transplantation and retinal prosthesis) which, in order to restore the functioning of the damaged retina, would require an intact downstream neuronal circuitry for the correct processing of the visual signal.

\section{Conclusions}

The data in literature to date show that both in glaucoma and macular degeneration the CNS is affected by morphological and functional alterations. These alterations are limited to visual areas in $\mathrm{MD}$, while involve multiple brain areas in glaucoma. The causes and mechanisms at the base of these modifications are not yet clear: the main hypotheses are ascribable to a mechanism of transsynaptic degeneration linked to functional deprivation following retinal damage; to the activation of normally silent collateral circuits; to involutionary mechanisms similar to those proper to primitive neurodegenerative pathologies such as Alzheimer's disease and to remodelling through neuronal plasticity but, in particular with regard to the last two points, evidence are not yet definitive. If it is legitimate to suppose that these modifications, which have been shown to have (at least partially) adaptive meaning, could favour a rehabilitation path compensating for the damage consequent to the pathology, it is also true that they could hinder the therapeutic strategies currently under development with the aim of restoring the damaged neuroretina: if these modifications were not reversible, the change in the neural networks at the basis of the connection existing between the retina and the brain, and between the different areas of the brain, would hinder the correct processing of the visual signal. This problem could occur mainly in glaucoma, which shows a widespread involvement in a large part of the CNS, rather than in MD where the modifications are more isolated at the posterior pole. It is therefore necessary to obtain more evidence both regarding an improved characterisation of the alterations existing in these patients (the results found in current literature were not always of unequivocal interpretation, due to the heterogeneity of patients' characteristics, stage of illness, used stimuli, type of analysis carried out and studied brain areas) and to investigate whether these changes could be reversible or not.

\section{Author Contributions}

Both authors gave their substantial contribution to conception and design of the manuscript and to the acquisition and interpretation of data and materials. Both authors gave their contribution in drafting the manuscript and in its critical revision for important intellectual content. Both authors have approved the manuscript in its present form for publication. Both authors agreed to be accountable for all aspects of the work in ensuring that questions related to the accuracy or integrity of any part of the work are appropriately investigated and resolved.

\section{Disclosure}

The authors reported no conflicts of interest for this work and declare that the research was conducted in the absence of any commercial or financial relationships that could be construed as a potential conflict of interest.

\section{References}

1. Pascolini D, Mariotti SP. Global estimates of visual impairment: 2010. Br J Ophthalmol. 2012;96:614-618. doi:10.1136/bjophthalmol-2011300539

2. Zhang Y, Jin G, Fan M, et al. Time trends and heterogeneity in the disease burden of glaucoma, 1990-2017: a global analysis. J Glob Health. 2019;9:20436. doi:10.7189/jogh.09.020436

3. Wong WL, Su X, Li X, et al. Global prevalence of age-related macular degeneration and disease burden projection for 2020 and 2040: a systematic review and meta-analysis. Lancet Glob Heal. 2014;2: e106-e116. doi:10.1016/S2214-109X(13)70145-1

4. Zhou M, Duan PC, Liang JH, Zhang XF, Pan C-W. Geographic distributions of age-related macular degeneration incidence: a systematic review and meta-analysis. Br J Ophthalmol. 2020. doi:10.1136/bjophthalmol-2020-316820.

5. Nuzzi R, Dallorto L, Rolle T. Changes of visual pathway and brain connectivity in glaucoma: a systematic review. Front Neurosci. 2018;12:363. doi:10.3389/fnins.2018.00363

6. Nuzzi R, Dallorto L, Vitale A. Cerebral modifications and visual pathway reorganization in maculopathy: a systematic review. Front Neurosci. 2020;14. doi:10.3389/fnins.2020.00755

7. Allingham RR, Shields M. Shields' Textbook of Glaucoma. Kluwer/ Lippincott Williams \& Wilkins Health; 2011. 
8. Liu Y, Allingham RR. Major review: molecular genetics of primary open-angle glaucoma. Exp Eye Res. 2017;160:62-84.

9. Zabel P, Kaluzny JJ, Zabel K, et al. Quantitative assessment of retinal thickness and vessel density using optical coherence tomography angiography in patients with Alzheimer's disease and glaucoma. PLoS One. 2021;16:e248284. doi:10.21203/rs.3.rs43721/v1.

10. Rao HL, Pradhan ZS, Suh MH, et al. Optical coherence tomography angiography in glaucoma. J Glaucoma. 2020;29:312-321. doi:10.1097/IJG.0000000000001463

11. Oddone F, Lucenteforte E, Michelessi M, et al. Macular versus retinal nerve fiber layer parameters for diagnosing manifest glaucoma: a systematic review of diagnostic accuracy studies. Ophthalmology. 2016;123:939-949. doi:10.1016/j. ophtha.2015.12.041

12. Kim NR, Lee ES, Seong GJ, et al. Structure-function relationship and diagnostic value of macular ganglion cell complex measurement using Fourier-domain OCT in glaucoma. Investig Ophthalmol Vis Sci. 2010;51:4646-4651. doi:10.1167/iovs.095053

13. Bočková $M$, Veselý $P$, Synek $S$, et al. Senzitivita a specificita spektrálního OCT u pacientů $\mathrm{s}$ počínajícím glaukomovým onemocněním. 2019.

14. Oboudiyat C, Glazer H, Isaacson RS, Seifan A, Greer C. Alzheimer's disease. Semin Neurol. 2013;33:313-329. doi:10.1055/s-0033-1359319

15. Chan VTT, Sun Z, Tang S, et al. Spectral domain-optical coherence tomography measurements in Alzheimer's disease: a systematic review and meta-analysis. Ophthalmology. 2020;126:497-510.

16. Tsokolas G, Tsaousis KT, Diakonis VF, Matsou A, Tyradellis S. Optical coherence tomography angiography in neurodegenerative diseases: a review. Eye Brain. 2020;12:73-87. doi:10.2147/EB. S193026

17. Garhöfer G, Fuchsjäger-Mayrl G, Vass C, et al. Retrobulbar blood flow velocities in open angle glaucoma and their association with mean arterial blood pressure. Investig Ophthalmol Vis Sci. 2010;51:6652-6657. doi:10.1167/iovs.10-5490

18. Bata AM, Fondi K, Witkowska KJ, et al. Optic nerve head blood flow regulation during changes in arterial blood pressure in patients with primary open-angle glaucoma. Acta Ophthalmol. 2019;97:e36-e41. doi:10.1111/aos.13850

19. Kromer R, Glusa P, Framme C, Pielen A, Junker B. Optical coherence tomography angiography analysis of macular flow density in glaucoma. Acta Ophthalmol. 2019;97:e199-e206. doi:10.1111/aos.13914

20. Takusagawa HL, Liu L, Ma KN, et al. Projection-resolved optical coherence tomography angiography of macular retinal circulation in glaucoma. Ophthalmology. 2017;124:1589-1599. doi:10.1016/ j.ophtha.2017.06.002

21. Milani P, Bochicchio S, Urbini LE, et al. Diurnal measurements of macular thickness and vessel density on OCT angiography in healthy eyes and those with ocular hypertension and glaucoma. J Glaucoma. 2020;29:918-925. doi:10.1097/ IJG.0000000000001580

22. Zabel K, Zabel P, Kaluzna M, et al. Correlation of retinal sensitivity in microperimetry with vascular density in optical coherence tomography angiography in primary open-angle glaucoma. PLoS One. 2020;15:1-18. doi:10.1371/journal.pone.0235571

23. Bulut M, Kurtuluş F, Gözkaya O, et al. Evaluation of optical coherence tomography angiographic findings in Alzheimer's type dementia. $\mathrm{Br} \quad J$ Ophthalmol. 2018;102:233-237. doi:10.1136/bjophthalmol-2017-310476
24. Jiang H, Wei Y, Shi Y, et al. Altered macular microvasculature in mild cognitive impairment and Alzheimer disease. $J \quad$ Neuro-Ophthalmol. 2018;38:292-298. doi:10.1097/ WNO.0000000000000580

25. Gauthier AC, Liu J. Neurodegeneration and neuroprotection in glaucoma. Yale J Biol Med. 2016;89:73-79.

26. Cvenkel B, Kolko M. Current medical therapy and future trends in the management of glaucoma treatment. $J$ Ophthalmol. 2020;2020:6138132. doi:10.1155/2020/6138132

27. Lambert NG, ElShelmani H, Singh MK, et al. Risk factors and biomarkers of age-related macular degeneration. Prog Retin Eye Res. 2016;54:64-102.

28. Chichagova V, Hallam D, Collin J, et al. Cellular regeneration strategies for macular degeneration: past, present and future. Eye. 2018;32:946-971. doi:10.1038/s41433-018-0061-z

29. Yang S, Cacquevel M, Saksida LM, et al. Perineuronal net digestion with chondroitinase restores memory in mice with tau pathology. Exp Neurol. 2015;265:48-58. doi:10.1016/j. expneurol.2014.11.013

30. de Winter F, Kwok JCF, Fawcett JW, et al. The chemorepulsive protein semaphorin $3 \mathrm{~A}$ and perineuronal net-mediated plasticity. Neural Plast. 2016;2016:3679545. doi:10.1155/ 2016/3679545

31. Foscarin S, Raha-Chowdhury R, Fawcett JW, Kwok JCF. Brain ageing changes proteoglycan sulfation, rendering perineuronal nets more inhibitory. Aging. 2017;9:1607-1622. doi:10.18632/ aging. 101256

32. Restani L, Caleo M. Reorganization of visual callosal connections following alterations of retinal input and brain damage. Front Syst Neurosci. 2016;10:86. doi:10.3389/fnsys.2016.00086

33. Fawcett J. Molecular control of brain plasticity and repair. Prog Brain Res. 2009;175:501-509.

34. Kwok JCF, Afshari F, García-Alías G, Fawcett JW. Proteoglycans in the central nervous system: plasticity, regeneration and their stimulation with chondroitinase ABC. Restor Neurol Neurosci. 2008;26:131-145.

35. Garaci FG, Bolacchi F, Cerulli A, et al. Optic nerve and optic radiation neurodegeneration in patients with glaucoma: in vivo analysis with 3-T diffusion-tensor MR imaging. Radiology. 2009;252:496-501. doi:10.1148/radiol.2522081240

36. Bolacchi F, Garaci FG, Martucci A, et al. Differences between proximal versus distal intraorbital optic nerve diffusion tensor magnetic resonance imaging properties in glaucoma patients. Invest Ophthalmol Vis Sci. 2012;53:4191-4196. doi:10.1167/ iovs.11-9345

37. Nucci C, Mancino R, Martucci A, et al. 3-T diffusion tensor imaging of the optic nerve in subjects with glaucoma: correlation with GDx-VCC, HRT-III and stratus optical coherence tomography findings. Br J Ophthalmol. 2012;96:976-980. doi:10.1136/ bjophthalmol-2011-301280

38. Zhang YQ, Li J, Xu L, et al. Anterior visual pathway assessment by magnetic resonance imaging in normal-pressure glaucoma. Acta Ophthalmol. 2012;90:e295-302. doi:10.1111/j.17553768.2011.02346.x

39. Wang MY, Wu K, Xu JM, et al. Quantitative 3-T diffusion tensor imaging in detecting optic nerve degeneration in patients with glaucoma: association with retinal nerve fiber layer thickness and clinical severity. Neuroradiology. 2013;55:493-498. doi:10.1007/ s00234-013-1133-1

40. Omodaka K, Murata T, Sato S, et al. Correlation of magnetic resonance imaging optic nerve parameters to optical coherence tomography and the visual field in glaucoma. Clin Experiment Ophthalmol. 2014;42:360-368. doi:10.1111/ceo.12237 
41. Chen Z, Lin F, Wang J, et al. Diffusion tensor magnetic resonance imaging reveals visual pathway damage that correlates with clinical severity in glaucoma. Clin Experiment Ophthalmol. 2013;41:43-49. doi:10.1111/j.1442-9071.2012.02832.x

42. Frezzotti P, Giorgio A, Motolese I, et al. Structural and functional brain changes beyond visual system in patients with advanced glaucoma. PLoS One. 2014;9:e105931. doi:10.1371/journal. pone.0105931

43. Frezzotti P, Giorgio A, Toto F, De Leucio A, De Stefano N. Early changes of brain connectivity in primary open angle glaucoma. Hum Brain Mapp. 2016;37:4581-4596. doi:10.1002/ hbm. 23330

44. Kaushik M, Graham SL, Wang C, Klistorner A. A topographical relationship between visual field defects and optic radiation changes in glaucoma. Invest Ophthalmol Vis Sci. 2014;55:5770-5775. doi:10.1167/iovs.14-14733

45. Zhou W, Muir ER, Chalfin S, Nagi KS, Duong TQ. MRI study of the posterior visual pathways in primary open angle glaucoma. J Glaucoma. 2017;26:173-181. doi:10.1097/ IJG.0000000000000558

46. Giorgio A, Zhang J, Costantino F, De Stefano N, Frezzotti P. Diffuse brain damage in normal tension glaucoma. Hum Brain Mapp. 2018;39:532-541. doi:10.1002/hbm.23862

47. El-Rafei A, Engelhorn T, Wärntges S, et al. A framework for voxel-based morphometric analysis of the optic radiation using diffusion tensor imaging in glaucoma. Magn Reson Imaging. 2011;29:1076-1087. doi:10.1016/j.mri.2011.02.034

48. El-Rafei A, Engelhorn T, Wärntges S, et al. Glaucoma classification based on visual pathway analysis using diffusion tensor imaging. Magn Reson Imaging. 2013;31:1081-1091. doi:10.1016/j.mri.2013.01.001

49. Engelhorn T, Michelson G, Waerntges S, et al. Diffusion tensor imaging detects rarefaction of optic radiation in glaucoma patients. Acad Radiol. 2011;18:764-769. doi:10.1016/j. acra.2011.01.014

50. Hernowo AT, Boucard CC, Jansonius NM, Hooymans JMM, Cornelissen FW. Automated morphometry of the visual pathway in primary open-angle glaucoma. Invest Ophthalmol Vis Sci. 2011;52:2758-2766. doi:10.1167/iovs.10-5682

51. Lu P, Shi L, Du H, et al. Reduced white matter integrity in primary open-angle glaucoma: a DTI study using tract-based spatial statistics. J Neuroradiol. 2013;40:89-93. doi:10.1016/j. neurad.2012.04.001

52. Michelson G, Engelhorn T, Wärntges S, et al. DTI parameters of axonal integrity and demyelination of the optic radiation correlate with glaucoma indices. Graefe's Arch Clin Exp Ophthalmol = Albr Von Graefes Arch Fur Klin Und Exp Ophthalmol. 2013;251:243-253. doi:10.1007/s00417-011-1887-2

53. Schoemann J, Engelhorn T, Waerntges S, et al. Cerebral microinfarcts in primary open-angle glaucoma correlated with DTI-derived integrity of optic radiation. Invest Ophthalmol Vis Sci. 2014;55:7241-7247. doi:10.1167/iovs.14-14919

54. Sidek S, Ramli N, Rahmat K, et al. Glaucoma severity affects diffusion tensor imaging (DTI) parameters of the optic nerve and optic radiation. Eur J Radiol. 2014;83:1437-1441. doi:10.1016/j. ejrad.2014.05.014

55. Gerente VM, Schor RR, Chaim KT, et al. Evaluation of glaucomatous damage via functional magnetic resonance imaging, and correlations thereof with anatomical and psychophysical ocular findings. PLoS One. 2015;10:e0126362. doi:10.1371/journal. pone. 0126362

56. Huang X, Zhong YL, Zeng XJ, et al. Disturbed spontaneous brain activity pattern in patients with primary angle-closure glaucoma using amplitude of low-frequency fluctuation: a fMRI study. Neuropsychiatr Dis Treat. 2015;11:1877-1883. doi:10.2147/ NDT.S87596
57. Murai H, Suzuki Y, Kiyosawa M, et al. Cerebral glucose metabolism in the striate cortex positively correlates with fractional anisotropy values of the optic radiation in patients with glaucoma. Clin Experiment Ophthalmol. 2015;43:711-719. doi:10.1111/ ceo. 12543

58. Tellouck L, Durieux M, Coupé P, et al. Optic radiations microstructural changes in glaucoma and association with severity: a study using 3Tesla-magnetic resonance diffusion tensor imaging. Invest Ophthalmol Vis Sci. 2016;57:6539-6547. doi:10.1167/iovs.16-19838

59. Jiang MM, Zhou Q, Liu XY, et al. Structural and functional brain changes in early- and mid-stage primary open-angle glaucoma using voxel-based morphometry and functional magnetic resonance imaging. Medicine. 2017;96:e6139. doi:10.1097/ MD.0000000000006139

60. Li T, Qu X, Chen W, et al. Altered information flow and microstructure abnormalities of visual cortex in normal-tension glaucoma: evidence from resting-state fMRI and DKI. Brain Res. 2020;1741:146874. doi:10.1016/j.brainres.2020.146874

61. Wang Q, Chen W, Wang H, et al. Reduced functional and anatomic interhemispheric homotopic connectivity in primary open-angle glaucoma: a combined resting state-fMRI and DTI study. Investig Ophthalmol Vis Sci. 2018;59:1861-1868. doi:10.1167/iovs.17-23291

62. Qu X, Wang Q, Chen W, et al. Combined machine learning and diffusion tensor imaging reveals altered anatomic fiber connectivity of the brain in primary open-angle glaucoma. Brain Res. 2019;1718:83-90. doi:10.1016/j.brainres.2019.05.006

63. Boucard CC, Hanekamp S, Ćurčić-blake B, et al. Neurodegeneration beyond the primary visual pathways in a population with a high incidence of normal-pressure glaucoma. Ophthalmic Physiol Opt. 2016;36:344-353. doi:10.1111/opo.12297

64. Zikou AK, Kitsos G, Tzarouchi LC, et al. Voxel-based morphometry and diffusion tensor imaging of the optic pathway in primary open-angle glaucoma: a preliminary study. AJNR Am $J$ Neuroradiol. 2012;33:128-134. doi:10.3174/ajnr.A2714

65. Dai H, Morelli JN, Ai F, et al. Resting-state functional MRI: functional connectivity analysis of the visual cortex in primary open-angle glaucoma patients. Hum Brain Mapp. 2013;34:2455-2463. doi:10.1002/hbm.22079

66. Ghiso JA, Doudevski I, Ritch R, Rostagno AA. Alzheimer's disease and glaucoma: mechanistic similarities and differences. J Glaucoma. 2013;22(Suppl 5):S36-8. doi:10.1097/ IJG.0b013e3182934af6

67. Li C, Cai P, Shi L, et al. Voxel-based morphometry of the visual-related cortex in primary open angle glaucoma. Curr Eye Res. 2012;37:794-802. doi:10.3109/02713683.2012.683506

68. Chen WW, Wang N, Cai S, et al. Structural brain abnormalities in patients with primary open-angle glaucoma: a study with 3T MR imaging. Invest Ophthalmol Vis Sci. 2013;54:545-554. doi:10.1167/iovs.12-9893

69. Williams AL, Lackey J, Wizov SS, et al. Evidence for widespread structural brain changes in glaucoma: a preliminary voxel-based MRI study. Invest Ophthalmol Vis Sci. 2013;54:5880-5887. doi:10.1167/iovs.13-11776

70. Zhang S, Wang B, Xie Y, et al. Retinotopic changes in the gray matter volume and cerebral blood flow in the primary visual cortex of patients with primary open-angle glaucoma. Invest Ophthalmol Vis Sci. 2015;56:6171-6178. doi:10.1167/iovs.15-17286

71. Wang J, Li T, Sabel BA, et al. Structural brain alterations in primary open angle glaucoma: a 3T MRI study. Sci Rep. 2016;6:18969. doi:10.1038/srep18969

72. Boucard CC, Hoogduin JM, van der Grond J, Cornelissen FW. Occipital proton magnetic resonance spectroscopy (1H-MRS) reveals normal metabolite concentrations in retinal visual field defects. PLoS One. 2007;2:e222. doi:10.1371/journal.pone.0000222 
73. Yu L, Xie B, Yin X, et al. Reduced cortical thickness in primary open-angle glaucoma and its relationship to the retinal nerve fiber layer thickness. PLoS One. 2013;8:e73208. doi:10.1371/journal. pone. 0073208

74. Calkins DJ, Horner PJ. The cell and molecular biology of glaucoma: axonopathy and the brain. Invest Ophthalmol Vis Sci. 2012;53:2482-2484. doi:10.1167/iovs.12-9483i

75. Cai F, Gao L, Gong H, et al. Network centrality of resting-state fMRI in primary angle-closure glaucoma before and after surgery. PLoS One. 2015;10:e0141389. doi:10.1371/journal.pone.0141389

76. Duncan RO, Sample PA, Weinreb RN, Bowd C, Zangwill LM. Retinotopic organization of primary visual cortex in glaucoma: a method for comparing cortical function with damage to the optic disk. Invest Ophthalmol Vis Sci. 2007;48:733-744. doi:10.1167/iovs.06-0773

77. Qing G, Zhang S, Wang B, Functional WN. MRI signal changes in primary visual cortex corresponding to the central normal visual field of patients with primary open-angle glaucoma. Invest Ophthalmol Vis Sci. 2010;51:4627-4634. doi:10.1167/ iovs.09-4834

78. Lestak J, Tintera J, Svata Z, Ettler L, Rozsival P. Glaucoma and CNS. Comparison of fMRI results in high tension and normal tension glaucoma. Biomed Pap Med Fac Univ Palacky, Olomouc, Czechoslov. 2014;158:144-153. doi:10.5507/bp.2013.038

79. Borges VM, Danesh-Meyer HV, Black JM, Thompson B. Functional effects of unilateral open-angle glaucoma on the primary and extrastriate visual cortex. $J$ Vis. 2015;15:9. doi:10.1167/15.15.9

80. Murphy MC, Conner IP, Teng CY, et al. Retinal structures and visual cortex activity are impaired prior to clinical vision loss in glaucoma. Sci Rep. 2016;6:31464. doi:10.1038/srep31464

81. Zhang P, Wen W, Sun X, He S. Selective reduction of fMRI responses to transient achromatic stimuli in the magnocellular layers of the LGN and the superficial layer of the SC of early glaucoma patients. Hum Brain Mapp. 2016;37:558-569. doi:10.1002/hbm.23049

82. Song $\mathrm{X}$, Wang $\mathrm{G}$, Zhang $\mathrm{T}$, et al. Functional magnetic resonance imaging evaluation of visual cortex activation in patients with anterior visual pathway lesions. Neural Regen Res. 2012;7:692-696. doi:10.3969/j.issn.1673-5374.2012.09.009

83. Wang Q, Chen W, Qu X, et al. Reduced cerebral blood flow in the visual cortex and its correlation with glaucomatous structural damage to the retina in patients with mild to moderate primary open-angle glaucoma. J Glaucoma. 2018;27:816-822. doi:10.1097/IJG.0000000000001017

84. Wang Q, Qu X, Chen W, et al. Altered coupling of cerebral blood flow and functional connectivity strength in visual and higher order cognitive cortices in primary open angle glaucoma. J Cereb Blood Flow Metab. 2020. doi:10.1177/0271678X20935274.

85. Wang J, Li T, Zhou P, et al. Altered functional connectivity within and between the default model network and the visual network in primary open-angle glaucoma: a resting-state fMRI study. Brain Imaging Behav. 2017;11:1154-1163. doi:10.1007/s11682-0169597-3

86. Wang J, Li T, Wang N, Xian J, He H. Graph theoretical analysis reveals the reorganization of the brain network pattern in primary open angle glaucoma patients. Eur Radiol. 2016;26:3957-3967. doi:10.1007/s00330-016-4221-x

87. Li T, Liu Z, Li J, et al. Altered amplitude of low-frequency fluctuation in primary open-angle glaucoma: a resting-state fMRI study. Investig Ophthalmol Vis Sci. 2014;56:322-329. doi:10.1167/iovs.14-14974

88. Chen W, Zhang L, Xu YG, Zhu K, Luo M. Primary angle-closure glaucomas disturb regional spontaneous brain activity in the visual pathway: an fMRI study. Neuropsychiatr Dis Treat. 2017;13:1409-1417. doi:10.2147/NDT.S134258
89. Agorastos A, Skevas C, Matthaei M, et al. Depression, anxiety, and disturbed sleep in glaucoma. $J$ Neuropsychiatry Clin Neurosci. 2013;25:205-213. doi:10.1176/appi. neuropsych. 12020030

90. Kong X, Yan M, Sun X, Xiao Z. Anxiety and depression are more prevalent in primary angle closure glaucoma than in primary open-angle glaucoma. $J$ Glaucoma. 2015;24:e57-63. doi:10.1097/IJG.0000000000000025

91. Minosse S, Garaci F, Martucci A, et al. Primary open angle glaucoma is associated with functional brain network reorganization. Front Neurol. 2019;10:1134. doi:10.3389/ fneur.2019.01134

92. Trivedi V, Bang JW, Parra C, et al. Widespread brain reorganization perturbs visuomotor coordination in early glaucoma. Sci Rep. 2019;9:14168. doi:10.1038/s41598-019-50793-x

93. Hernowo AT, Prins D, Baseler HA, et al. Morphometric analyses of the visual pathways in macular degeneration. Cortex. 2014;56:99-110. doi:10.1016/j.cortex.2013.01.003

94. Boucard CC, Hernowo AT, Maguire RP, et al. Changes in cortical grey matter density associated with long-standing retinal visual field defects. Brain. 2009;132:1898-1906. doi:10.1093/brain/ awp119

95. Plank T, Frolo J, Brandl-Rühle S, et al. Gray matter alterations in visual cortex of patients with loss of central vision due to hereditary retinal dystrophies. Neuroimage. 2011;56:1556-1565. doi:10.1016/j.neuroimage.2011.02.055

96. Olivo G, Melillo P, Cocozza S, et al. Cerebral involvement in Stargardt's disease: a VBM and TBSS study. Invest Ophthalmol Vis Sci. 2015;56:7388-7397. doi:10.1167/iovs.15-16899

97. Little DM, Thulborn KR, Szlyk JP. An FMRI study of saccadic and smooth-pursuit eye movement control in patients with age-related macular degeneration. Invest Ophthalmol Vis Sci. 2008;49:1728-1735. doi:10.1167/iovs.07-0372

98. Szlyk JP, Little DM. An FMRI study of word-level recognition and processing in patients with age-related macular degeneration. Invest Ophthalmol Vis Sci. 2009;50:4487-4495. doi:10.1167/ iovs.08-2258

99. Lešták J, Tintěra J, Karel I, Svatá Z, Rozsíval P. Functional magnetic resonance imaging in patients with the wet form of age-related macular degeneration. Neuroophthalmology. 2013;37:192-197. doi:10.3109/01658107.2013.819581

100. Plank T, Frolo J, Farzana F, et al. Neural correlates of visual search in patients with hereditary retinal dystrophies. Hum Brain Mapp. 2013;34:2607-2623. doi:10.1002/hbm.22088

101. Plank T, Frolo J, Brandl-Rühle S, et al. fMRI with central vision loss: effects of fixation locus and stimulus type. Optom Vis Sci. 2017;94:297-310. doi:10.1097/OPX.0000000000001047

102. Rosengarth K, Keck I, Brandl-Rühle S, et al. Functional and structural brain modifications induced by oculomotor training in patients with age-related macular degeneration. Front Psychol. 2013;4:428. doi:10.3389/fpsyg.2013.00428

103. Liu T, Cheung S-H, Schuchard RA, et al. Incomplete cortical reorganization in macular degeneration. Invest Ophthalmol Vis Sci. 2010;51:6826-6834. doi:10.1167/iovs.09-4926

104. Schumacher EH, Jacko JA, Primo SA, et al. Reorganization of visual processing is related to eccentric viewing in patients with macular degeneration. Restor Neurol Neurosci. 2008;26:391-402.

105. Masuda Y, Dumoulin SO, Nakadomari S, Wandell BA. V1 projection zone signals in human macular degeneration depend on task, not stimulus. Cereb Cortex. 2008;18:2483-2493. doi:10.1093/cercor/bhm256

106. Baker CI, Dilks DD, Peli E, Kanwisher N. Reorganization of visual processing in macular degeneration: replication and clues about the role of foveal loss. Vision Res. 2008;48:1910-1919. doi:10.1016/j.visres.2008.05.020 
107. Plank T, Rosengarth K, Schmalhofer C, et al. Perceptual learning in patients with macular degeneration. Front Psychol. 2014;5:1189. doi:10.3389/fpsyg.2014.01189

108. Haak KV, Morland AB, Rubin GS, Cornelissen FW. Preserved retinotopic brain connectivity in macular degeneration. Ophthalmic Physiol Opt. 2016;36:335-343. doi:10.1111/opo.12279

109. Sabel BA, Gudlin J. Vision restoration training for glaucoma: a randomized clinical trial. JAMA Ophthalmol. 2014;132:381-389. doi:10.1001/jamaophthalmol.2013.7963

110. Markowitz M, Daibert-Nido M, Markowitz SN. Rehabilitation of reading skills in patients with age-related macular degeneration. Can J Ophthalmol. 2018;53:3-8. doi:10.1016/j.jcjo.2017.10.042

111. Hooper P, Jutai JW, Strong G, Russell-Minda E. Age-related macular degeneration and low-vision rehabilitation: a systematic review. Can J Ophthalmol. 2008;43:180-187. doi:10.3129/108001

112. Venugopalan P, Wang Y, Nguyen T, et al. Transplanted neurons integrate into adult retinas and respond to light. Nat Commun. 2016;7:10472. doi: $10.1038 /$ ncomms 10472

113. Mathieson K, Loudin J, Goetz G, et al. Photovoltaic retinal prosthesis with high pixel density. Nat Photonics. 2012;6:391-397. doi:10.1038/nphoton.2012.104

114. Jutley G, Luk SM, Dehabadi MH, Cordeiro MF. Management of glaucoma as a neurodegenerative disease. Neurodegener Dis Manag. 2017;7:157-172. doi:10.2217/nmt-2017-0004

115. Mandai M, Watanabe A, Kurimoto Y, et al. Autologous induced stem-cell-derived retinal cells for macular degeneration. $N$ Engl $J$ Med. 2017;376:1038-1046. doi:10.1056/NEJMoa1608368

116. Moore NA, Bracha P, Hussain RM, Morral N, Ciulla TA. Gene therapy for age-related macular degeneration. Expert Opin Biol Ther. 2017;17:1235-1244. doi:10.1080/14712598.2017.1356817

117. Xu XH, Zou JY, Geng W, Wang AY. Association between glaucoma and the risk of Alzheimer's disease: a systematic review of observational studies. Acta Ophthalmol. 2019;97:665-671. doi:10.1111/aos.14114

118. Sen S, Saxena R, Tripathi M, Vibha D, Dhiman R. Neurodegeneration in Alzheimer's disease and glaucoma: overlaps and missing links. Eye. 2020;34:1546-1553. doi:10.1038/ s41433-020-0836-x

119. London A, Benhar I, Schwartz M. The retina as a window to the brain - from eye research to CNS disorders. Nat Rev Neurol. 2013;9:44-53. doi:10.1038/nrneurol.2012.227
120. Janssen SF, Jansonius NM, Bouwman F, Verbraak FD, Bergen AA. Systematic review of the association between alzheimer's disease and chronic glaucoma. Clin Ophthalmol. 2015;9:783-784. doi:10.2147/OPTH.S83197

121. Schlötzer-Schrehardt U, Naumann GOH. Ocular and systemic pseudoexfoliation syndrome. Am J Ophthalmol. 2006;141:921937.e2. doi:10.1016/j.ajo.2006.01.047

122. Ekström C, Kilander L. Pseudoexfoliation and Alzheimer's disease: a population-based 30-year follow-up study. Acta Ophthalmol. 2014;92:355-358. doi:10.1111/aos.12184

123. Yilmaz A, Tamer L, Ateş NA, Çamdeviren H, Değirmenci U. Effects of apolipoprotein E genotypes on the development of exfoliation syndrome. Exp Eye Res. 2005;80:871-875. doi:10.1016/j.exer.2004.12.018

124. Krumbiegel M, Pasutto F, Mardin CY, et al. Apolipoprotein e genotypes in pseudoexfoliation syndrome and pseudoexfoliation glaucoma. J Glaucoma. 2010;19:561-565. doi:10.1097/ IJG.0b013e3181ca76c4

125. Abramsson A, Landgren S, Zetterberg M, et al. No association of LOXL1 gene polymorphisms with Alzheimer's disease. NeuroMolecular Med. 2011;13:160-166. doi:10.1007/s12017011-8144-z

126. Cumurcu T, Dorak F, Cumurcu BE, Erbay LG, Ozsoy E. Is there any relation between pseudoexfoliation syndrome and Alzheimer's type dementia? Semin Ophthalmol. 2013;28:224-229. doi:10.3109/ 08820538.2013.793726

127. Linnér E, Popovic V, Gottfries CG, et al. The exfoliation syndrome in cognitive impairment of cerebrovascular or Alzheimer's type. Acta Ophthalmol Scand. 2001;79:283-285. doi:10.1034/ j.1600-0420.2001.790314.x

128. $\mathrm{Xu} \mathrm{L,} \mathrm{You} \mathrm{QS,} \mathrm{Wang} \mathrm{YX,} \mathrm{Jonas} \mathrm{JB.} \mathrm{Cognitive} \mathrm{function} \mathrm{and}$ pseudoexfoliation syndrome. The Beijing Eye Study 2011. Br J Ophthalmol. 2013;97:1215. doi:10.1136/bjophthalmol-2012301906

129. Brodmann K. Vergleichende Lokalisationslehre der Grosshirnrinde in ihren Prinzipien dargestellt auf Grund des Zellenbaues [Comparative localization theory of the cerebral cortex presented in its principles on the basis of the cell structure]. Leipzig: Johann Ambrosius Barth Verlag; 1909. German.

130. Gray H. Anatomy of the Human Body. Philadelphia: Lea \& Febiger; 1983.
Eye and Brain

\section{Publish your work in this journal}

Eye and Brain is an international, peer-reviewed, open access journal focusing on clinical and experimental research in the field of neuroophthalmology. All aspects of patient care are addressed within the journal as well as basic research. Papers covering original research, basic science, clinical and epidemiological studies, reviews and

Submit your manuscript here: https://www.dovepress.com/eye-and-brain-journal evaluations, guidelines, expert opinion and commentary, case reports and extended reports are welcome. The manuscript management system is completely online and includes a very quick and fair peerreview system, which is all easy to use. Visit http://www.dovepress. com/testimonials.php to read real quotes from published authors. 